\title{
Airway Characteristics and Safe Management of Spontaneously Breathing Patients: Risks of Sedation and Analgesia and Changes in Wakefulness
}

\author{
Adrian Reber \\ Department of Anesthesia and Intensive Care Medicine, Hospital of Zollikerberg, Zollikerberg, Switzerland \\ Email: Adrian.reber@spitalzollikerberg.ch
}

How to cite this paper: Reber, A. (2016) Airway Characteristics and Safe Management of Spontaneously Breathing Patients: Risks of Sedation and Analgesia and Changes in Wakefulness. International Journal of Clinical Medicine, 7, 726-735.

http://dx.doi.org/10.4236/ijcm.2016.711079

Received: August 9, 2016

Accepted: October 29, 2016

Published: November 1, 2016

Copyright (c) 2016 by author and Scientific Research Publishing Inc. This work is licensed under the Creative Commons Attribution International License (CC BY 4.0).

http://creativecommons.org/licenses/by/4.0/

\begin{abstract}
The goal of safe airway management is to maintain a patent airway. Lack of knowledge of the anatomical morphology and changes that may occur in the upper airway during sedation and unconsciousness may lead to critical incidents and hazardous complications. This review focuses on the risks of sedation and analgesia and changes in wakefulness on airway patency in spontaneously breathing patients. Furthermore, key elements of airway management are presented and discussed.
\end{abstract}

\section{Keywords}

Airway, Analgesia, Anesthetics, Anesthesia, Breathing, Chin Lift, Diagnostics, Emergency, Jaw Thrust, Sedation, Maneuvers, Obesity,

Obstructive Sleep Apnea, Posture, Sleep

\section{Introduction}

In emergency situations (pre- and in-hospital) and in sedated patients (e.g., patients undergoing diagnostic procedures), failure to maintain a patent airway can lead to severe hypoxia and death. A comprehensive understanding of the anatomical morphology and changes in the upper airway geometry is crucial. Prediction methods are useful for identifying a potentially difficult airway. However, the predictive value of these methods is limited. This overview presents the airway characteristics and safe management of spontaneously breathing sedated patients. "Sedation and analgesia" encompasses different states such as minimal sedation (anxiolysis), moderate sedation and analgesia (conscious sedation), and deep sedation/analgesia through general anesthesia [1]. This 
overview determines the influence of moderate to deep sedation on upper airway patency. Definitions of levels of sedation are given in Table 1.

\section{Wakefulness and Sleep: Differences in Airway Patency}

The upper airway is a complex structure. Geometrical changes caused by changes in wakefulness are fundamental for understanding the limitations of airway patency. The tone of oropharyngeal muscles is maintained during spontaneous breathing. In conscious patients with a normal anatomical morphology, essential dynamic changes in the upper airway caliber occur during quiet respiration. During inspiration, negative intraluminal pressure is majorly balanced by the upper airway dilator muscles [2]. During expiration, the positive intraluminal pressure expands the upper airway [3]. These respiratory changes are more prominent in the lateral than in the anteroposterior dimension. Thus, in addition to the tongue and soft palate, lateral pharyngeal walls are one of the most important upper airway soft tissue structures [4]. During sleep, airway dimensional changes occur because of the changes in body position and soft tissue structures. The activity of upper airway dilator muscles decreases, resulting in a reduction in the upper airway size and an increase in upper airway resistance. The complex anatomical structure consists of muscles such as the tongue, palate muscles, pharyngeal constrictor muscles, genioglossal and geniohyoideus muscles, and the four infrahyoid muscles (sternohyoid, omohyoid, sternothyroid, and thyrohyoid). The male airway is substantially more collapsible than the female airway because of the pharyngeal airway length, an increased cross-sectional area of the soft palate, and an increased airway volume [4]. Magnetic resonance imaging (MRI) studies have shown that during sleep, the volume of the retropalatal airway decreased significantly by $19 \%(\mathrm{P}=0.03)$, whereas that of the retroglossal airway decreased slightly [5]. These findings suggest that the retropalatal region may be more likely to collapse.

\section{Sedation and Upper Airway}

Determinants of upper airway patency include airway caliber, transluminal pressure gradient, compliance of the airway wall, and upper airway muscle activation [6]. Sedatives impair upper airway stability, and upper airway obstruction is the only serious

Table 1. Differences in moderate and deep sedation and analgesia.

\begin{tabular}{ccc}
\hline & Depth of Sedation & \\
\hline Sedation and Analgesia & Moderate & Deep \\
Responsiveness & $\begin{array}{c}\text { Purposeful response to verbal } \\
\text { or tactile stimulation }\end{array}$ & $\begin{array}{c}\text { Purposeful response after } \\
\text { repeated or painful stimulation }\end{array}$ \\
Spontaneous breathing & Adequate & May be inadequate \\
Airway & No intervention required & Intervention may be required \\
Cardiovascular function & Usually maintained & Usually maintained
\end{tabular}

a. This table is adapted from [1]. 
adverse event that can occur during moderate or deep sedation [7]. Anatomical predisposition, unfavorable posture, and profound impairment of muscle activity increase the risk of airway obstruction. Airway narrowing leading to obstruction was investigated in children anesthetized with propofol [8]. Increasing depth of anesthesia lead to narrowing of the entire upper airway, which was most prominent at the level of the epiglottis. Mahmoud et al. compared propofol with dexmedetomidine and hypothesized that dexmedetomidine has lower effects on the upper airway tone than other sedatives or anesthetics and provides more favorable conditions, which are similar to those observed during natural sleep [9]. However, propofol is still the most commonly used intravenous anesthetic agent in many countries, since of its rapid onset and reversal of action. There is no reason to contraindicate propofol in patients allergic to eggs, soybean oil or peanuts [10].

Midazolam is the most commonly used benzodiazepine for sedation. Studies have shown that midazolam may lead to upper airway obstruction; however, its dose-dependent effect remains unclear [11].

Ketamine is the safest sedative for preventing upper airway collapse. In particular, during emergency situations, ketamine may be the drug of choice. It causes minimal respiratory drive suppression and minor impairment of respiratory muscle activity [12]. However, rapid administration of high doses of ketamine should be avoided because of the possibility of (transient) apnea [13].

Opioids depress both the ventilator and pharyngeal neuromotor drive [11]. Opioids impair upper airway patency through the activation of laryngeal adductor motoneurons and depression of laryngeal abductor and pharyngeal constrictor motoneurons.

The most common adverse reaction to opioids is nausea. In addition, except for fentanyl and its derivates, opioids can induce pseudoallergic reactions by triggering degranulation of mast cells and the direct release of histamine.

Because of high interindividual anatomic variability, different age-related characteristics, and various comorbidities, safe airway management must be tailored individually. Physiological derangements of the patient increase the risk of cardiovascular critical incidents and even cardiovascular collapse from airway management. Mosier et al. described the four physiologically difficult airways: hypoxemia, hypotension, severe metabolic acidosis, and right ventricular failure [14]. Thus, sedatives must be used cautiously in critically ill patients. Practice guidelines for sedation and analgesia by non-anesthesiologists have been outlined in a report by the American Society of Anesthesiologists Task Force [1]. Although capnography indicates respiratory depression earlier than pulse oximetry, its strict application during sedation is not established. However, as a tool providing breath-to-breath ventilation data, capnography has the potential to further reduce the incidence of serious adverse events due to inadvertent oversedation [15]. This non-invasive respiratory monitoring tool is applicable in different settings (e.g., emergency medical service, endoscopy units, radiology departments, and other treatment areas outside the operation theater). 


\section{Posture and Position of the Head in Sedated Patients}

\subsection{Position of the Body}

Unfavorable postures such as the supine position, neck flexion, and abnormal mouth opening may lead to impaired airway patency. A simple adjustment of the body position may support patency and reduce the probability of upper airway obstruction [16]. Isono, Tanaka, and Nishino reported that in patients with obstructive sleep apnea (OSA) syndrome, the lateral position reduced the effect of gravity on the soft palate, tongue, and epiglottis, thus structurally improving the maintenance of the passive pharynx [16]. Changing the patient's position from supine to lateral prevents the pharyngeal soft tissue from falling backward against the posterior pharyngeal wall. Litman et al. showed that lateral positioning widens all non-cartilaginous parts of the upper airway in children [17]. In morbid obesity, a "ramped" position is achieved by using an elevated pillow or by arranging blankets underneath the patient's upper body and head until a horizontal alignment between the external auditory meatus and sternal notch is obtained [18].

\subsection{Head and Neck Position}

Both flexion and hyperextension of the head and neck increase upper airway resistance. Particularly in patients prone to upper airway collapse, optimal head and neck positioning is mandatory. In unconscious patients, overflexion of the head causes complete airway obstruction. Caution should be exercised in patients with pharyngeal tumors. Extension is associated with the risk of airway occlusion, particularly in children, where anatomy is already narrow.

In adults, sniffing position has been considered the optimal head and neck position, aligning the laryngeal, pharyngeal, and oral axes. According to Jonathan Benumof, the sniffing position necessitates approximately $30^{\circ}-35^{\circ}$ of flexion of the neck axis on the chest axis [19]. In obese patients, anterior displacement of critical pharyngeal structures (such as epiglottis and base of the tongue) and positioning of the head may be limited. The sniffing position is prohibited in patients with atlantoaxial instability. In children with Down syndrome, the potential risk of cervical spine instability must be considered [20].

In infants, the prominent occiput reduces the degree of cervical extension during shoulder elevation; resulting in an equally favorable position compared with the sniffing position [21]. Vialet, Nau, Chaumoittre, and Martin demonstrated that slight extension of the head in infants and young children considerably improved the alignment of the axes of the airway [22]. Another MRI study showed that application of a soft neck collar in children aged 2 - 4 years may expand the retropalatal and retroglossal airway dimension during sedation in the supine position [23]. The underlying mechanism may be the slight extension of the head with anterior protrusion of the mandible achieved by the neck collar. Mustafa, Emara, and Nouh suggested that displacing the mandible pulls the tongue forward and subsequently increases the caliber of the retroglossal airway [23]. In addition, the retropalatal airway improves as the soft palate is displaced for- 
ward because it is coupled to the tongue through the fauces [24].

The optimal head position for maintaining airway patency depends on age. Head extension and neutral head position angles differ in preschool and school children. In preschool children, a neutral head position or head extension with an angle of $-1^{\circ}$ or $13^{\circ}$, and in school children, a head extension of $16^{\circ}$ may be used to achieve optimal ventilation in an unprotected airway [25]. MRI studies have shown that the upper airway configuration in snorers and apneic patients is different from that in normal people [3] (Figure 1).

Head rotation is practiced routinely (e.g., during endoscopy). In infants and newborns, this maneuver increases the collapsibility of the passive pharynx [26]. During drug-induced sleep endoscopy, patients with OSA syndrome showed similar sites, severity, and patterns of upper airway collapse with rotation of the head in the supine position and lateral head and trunk position [27]. However, the severity of the anteroposterior collapse at the level of the soft palate during head rotation is lower in the supine position than in the lateral and trunk position.

\section{Posture and Position of the Head in Sedated Patients}

Depending on the depth of sedation/analgesia and pre-existing airway abnormalities, airway collapsibility has to be prevented through body/head positioning and appropriate airway maneuvers.

\subsection{Chin Lift: A Single-Handed Maneuver}

Chin lift is the simplest method of ensuring an open airway in an unresponsive patient. The chin of the patient is lifted at the anterior border of the mental protuberance without protruding the mandible; in chin lift, the lips are in close contact. A patent nasal airway is crucial [28]. MRI findings have shown that combined mouth closure and chin lift widens the anteroposterior and transverse diameters of the entire pharyngeal airway. The degree of muscular tone in geniohyoid and genioglossus muscles plays a vital role. During general anesthesia with muscle paralysis, chin lift improves the flaccid upper airway state by increasing the glottic opening. However, in obligate mouth breathers such as children with large adenotonsillar hypertrophy (ATH) or patients with extreme obesity, chin lift should be avoided [29] [30].

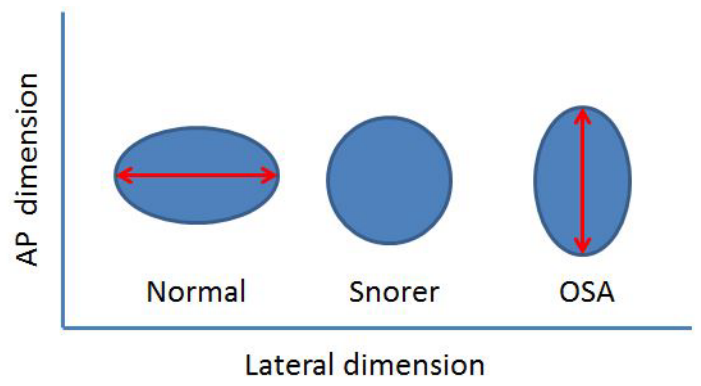

Figure 1. Differences in upper airway dimensions. This figure is adapted from [3]. AP = anteroposterior; OSA = obstructive sleep apnea. 


\subsection{Jaw Thrust: A Two-Handed Maneuver}

The jaws are displaced at the mandibular angles with both hands upward and anterior to open the mouth. In $90 \%$ of unconscious children ( 1 - 9 years old), jaw thrust restored the patent airway with no clinical signs of obstruction [31]. Chin lift had only a 50\% success rate in these patients, probably because of the high incidence of large ATH in this age group. However, jaw thrust can deteriorate upper airway patency in patients with large cervical masses in their lateral pharyngeal walls, which are probably caused by medial displacement of the tumorous tissue [32].

In unconscious infants, excessive jaw thrust with head tilt should be avoided because of the potential critical narrowing of the soft and pliable trachea. The pediatric basic life support guidelines of the American Heart Association still recommend the head tiltchin lift maneuver for both injured and non-injured patients [33]. These recommendations have not been discussed further in 2015 [33]. For children, discussions should be held to determine whether jaw thrust should be used carefully beginning with a slight pressure to open a potentially obstructed airway and to assess the patient's consciousness [34].

In patients with an unstable upper cervical spine, the jaw thrust maneuver results in less motion at an unstable $\mathrm{C} 1-\mathrm{C} 2$ injury compared with the head tilt-chin lift maneuver [35].

\subsection{Continuous Positive Airway Pressure}

Predicting the response of the patients to sedatives and analgesics may be difficult. In patients where the level of sedation becomes deeper than expected, respiratory instability has to be managed using ventilatory support. Continuous positive airway pressure (CPAP) applied to the airways throughout both inspiration and expiration is effective at maintaining airway patency in most patients. Jun et al. demonstrated that nasal CPAP produced more effective tidal volumes than full face mask CPAP and ventilation in unconscious patients [36].

In children with ATH and depending on open mouth breathing, chin lift does not improve or aggravate airway patency [28]. Moreover, application of jaw thrust with CPAP has been the most effective maneuver to overcome airway obstruction in these patients [37].

\section{Obesity and OSA}

Positioning of morbidly obese patients may be challenging. The reverse Trendelenburg position increases pulmonary compliance and functional residual capacity, thereby improving oxygenation compared with the supine position [38]. Obese patients have fatty tissue externally and increased adipose tissue in the upper airway soft tissue structures, mainly in the tongue, soft palate, lateral pharyngeal walls, and parapharyngeal fat pads [3]. Thus, the upper airways show increased collapsibility. Pharyngeal critical closing pressure is associated with the hyoid position [39]. Computed tomography analysis showed that tongue dimensions, pharyngeal length, and mandibular plane to hyoid 
muscles are associated with obesity variables (body mass index and neck and abdominal circumferences) [39]. In apneic patients, the thickness of the lateral pharyngeal walls and the more collapsible velopharynx are the predominant anatomic factors causing airway narrowing [3] [40].

Pien et al. re-examined the use of determining the critical closing pressure value from direct observation of occluded breaths (=no flow) [41]. They found that during overnight polysomnography, observed critical closing pressure values provide a consistent metric for describing hypotonic airway collapsibility in both subjects with and without OSA. OSA is a sleep-related breathing disorder characterized by repetitive episodes of airflow cessation. OSA patients are at increased risk of upper airway collapse and respiratory complications under the influence of sedatives and opioids [42]. CPAP application could improve airway patency in these patients [43]. Appropriate safety precautions must be taken to minimize the possibility of aspiration of gastric content [44].

\section{Conclusion}

Airway management in spontaneously breathing patients under moderate to deep sedation/analgesia is challenging. The goal is to provide these patients with the benefits of sedation/analgesia while minimizing the associated risks. A comprehensive understanding of the anatomical morphology and changes in the upper airway geometry is crucial. Because of high interindividual anatomic variability, different age-related characteristics, and various comorbidities, safe airway management with appropriate positioning and application of airway maneuvers has to be tailored individually. Emergency equipment should be available when sedatives or analgesic drugs are administered in order to rescue patients whose sedation level becomes deeper than initially intended.

\section{References}

[1] American Society of Anesthesiologists Task Force on Sedation and Analgesia by NonAnesthesiologists (2002) Practice Guidelines for Sedation and Analgesia by Non-Anesthesiologists. Anesthesiology, 96, 1004-1017. http://dx.doi.org/10.1097/00000542-200204000-00031

[2] Schwab, R.J., Gefter, W.B., Pack, A.I. and Hoffman, E.A. (1993) Dynamic Imaging of the Upper Airway during Respiration in Normal Subjects. Journal of Applied Physiology, 74, 1504-1514.

[3] Schwab, R.J. (1996) Properties of Tissues Surrounding the Upper Airway. Sleep, 19, S170S174.

[4] Malhotra, A., Huang, Y., Fogel, R.B., Pillar, G., Edwards, J.K., Kikinis, R., Loring, S.H. and White, D.P. (2002) The Male Predisposition to Pharyngeal Collapse: Importance of Airway Length. American Journal of Respiratory and Critical Medicine, 166, 1388-1395. http://dx.doi.org/10.1164/rccm.2112072

[5] Trudo, F.J., Gefter, W.B., Welch, K.C., Gupta, K.B., Maislin, G. and Schwab, R.J. (1998) State-Related Changes in Upper Airway Caliber and Surrounding Soft-Tissue Structures in Normal Subjects. American Journal of Respiratory and Critical Care Medicine, 158, 12591270. http://dx.doi.org/10.1164/ajrccm.158.4.9712063 
[6] Hillman, D.R., Platt, P.R. and Eastwood, P.R. (2010) Anesthesia, Sleep, and Upper Airway Collapsibility. Anesthesiology Clinics, 28, 443-455.

http://dx.doi.org/10.1016/j.anclin.2010.07.003

[7] Cravero, J.P., Beach, M.L., Blike, G.T., Gallagher, S.M., Hertzog, J.H. and Pediatric Sedation Research Consortium (2009) The Incidence and Nature of Adverse Events during Pediatric Sedation/Anesthesia with Propofol for Procedures Outside the Operating Room: A Report from the Pediatric Sedation Research Consortium. Anesthesia \& Analgesia, 108, 795-804. http://dx.doi.org/10.1213/ane.0b013e31818fc334

[8] Evans, R.G., Crawford, M.W., Noseworthy, M.D. and Yoo, S.J. (2003) Effect of Increasing Depth of Propofol Anesthesia on Upper Airway Configuration in Children. Anesthesiology, 99, 596-602. http://dx.doi.org/10.1097/00000542-200309000-00014

[9] Mahmoud, M., Gunter, J., Donnelly, L.F., Wang, Y., Nick, T.G. and Sadhasivam, S. (2009) A Comparison of Dexmedetomidine with Propofol for Magnetic Resonance Imaging Sleep Studies in Children. Anesthesthesia \& Analgesia, 109, 745-753. http://dx.doi.org/10.1213/ane.0b013e3181adc506

[10] Dewachter, P., Mouton-Faivre, C., Castells, M.C. and Hepner, D.L. (2011) Anesthesia in the Patient with Multiple Drug Allergies: Are all Allergies the Same? Current Opinion in Anesthesiology, 24, 320-325. http://dx.doi.org/10.1097/ACO.0b013e3283466c13

[11] Ehsan, Z., Mahmoud, M., Shott, S.R., Amin, R.S. and Ishman, S.L. (2016) The Effects of Anesthesia and Opioids on the Upper Airway: A Systematic Review. Laryngoscope, 126, 270-284. http://dx.doi.org/10.1002/lary.25399

[12] Lu, J., Nelson, L.E., Franks, N., Maze, M., Chamberlin, N.L. and Saper, C.B. (2008) Role of Endogenous Sleep-Wake and Analgesic Systems in Anesthesia. The Journal of Comparative Neurology, 508, 648-662. http://dx.doi.org/10.1002/cne.21685

[13] Green, S.M., Rothrock, S.G., Lynch, E.L., Ho, M., Harris, T., Hestdalen, R., Hopkins, G.A., Garrett, W. and Westcott, K. (1998) Intramuscular Ketamine for Pediatric Sedation in the Emergency Department: Safety Profile in 1022 Cases. Annals of Emergency Medicine, 31, 688-697. http://dx.doi.org/10.1016/S0196-0644(98)70226-4

[14] Mosier, J.M., Joshi, R., Hypes, C., Pacheco, G., Valenzuela, T. and Sakles, J.C. (2015) The Physiologically Difficult Airway. Western Journal of Emergency Medicine, 16, 1109-1117. http://dx.doi.org/10.5811/westjem.2015.8.27467

[15] Adams, L., Butas, S. and Spurlock Jr., D. (2015) Capnography (ETCO2), Respiratory Depression, and Nursing Interventions in Moderately Sedated Adults Undergoing Transesophageal Echocardiography (TEE). Journal of Perianesthesia Nursing, 30, 14-22. http://dx.doi.org/10.1016/j.jopan.2013.07.009

[16] Isono, S., Tanaka, A. and Nishino, T. (2002) Lateral Position Decreases Collapsibility of the Passive Pharynx in Patients with Obstructive Sleep Apnea. Anesthesiology, 97, 780-785. http://dx.doi.org/10.1097/00000542-200210000-00006

[17] Litman, R.S., Wake, N., Chan, L.M., McDonough, J.M., Sin, S., Mahboubi, S. and Arens, R. (2005) Effect of Lateral Positioning on Upper Airway Size and Morphology in Sedated Children. Anesthesiology. 103, 484-488. http://dx.doi.org/10.1097/00000542-200509000-00009

[18] Collins, J.S., Lemmens, H.J., Brodsky, J.B., Brock-Utne, J.G. and Levitan, R.M. (2004) Laryngoscopy and Morbid Obesity: A Comparison of the "Sniff" and "Ramped" Positions. Obesity Surgery, 14, 1171-1175. http://dx.doi.org/10.1381/0960892042386869

[19] Benumof, J.L. (2000) Patient in "Sniffing Position". Anesthesiology, 93, 1365-1366 http://dx.doi.org/10.1097/00000542-200011000-00045 
[20] Lewanda, A.F., Matisoff, A., Revenis, M., Harahsheh, A., Futterman, C., Nino, G., Greenberg. J., Myseros, J.S., Rosenbaum, K.N. and Summar, M. (2016) Preoperative Evaluation and Comprehensive Risk Assessment for Children with Down Syndrome. Paediatric Anaesthesia, 26, 356-362. http://dx.doi.org/10.1111/pan.12841

[21] Shorten, G.D., Armstrong, D.C., Roy, W.I. and Brown, L. (1995) Assessment of the Effect of Head and Neck Position on Upper Airway Anatomy in Sedated Paediatric Patients Using Magnetic Resonance Imaging. Pediatric Anesthesia, 5, 243-248.

http://dx.doi.org/10.1111/j.1460-9592.1995.tb00292.x

[22] Vialet, R., Nau, A., Chaumoître, K. and Martin, C. (2008) Effects of Head Posture on the Oral, Pharyngeal and Laryngeal Axis Alignment in Infants and Young Children by Magnetic Resonance Imaging. Paediatric Anaesthesia, 18, 525-531. http://dx.doi.org/10.1111/j.1460-9592.2008.02530.x

[23] Moustafa, M.A., Emara, D.M. and Nouh, M.R. (2015) Effect of a Neck Collar on Upper Airway Size in Children Sedated with Propofol-Midazolam Combination during Magnetic Resonance Imaging. Paediatric Anaesthesia, 25, 421-427. http://dx.doi.org/10.1111/pan.12593

[24] Isono, S., Tanaka, A., Sho, Y., Konno, A. and Nishino, T. (1995) Advancement of the Mandible Improves Velopharyngeal Airway Patency. Journal of Applied Physiology, 79, 2132-2138.

[25] Paal, P., Niederklapfer, T., Keller, C., von Goedecke, A., Luckner, G., Pehboeck, D., Mitterlechner, T., Herff, H., Riccabona, U. and Wenzel, V. (2010) Head-Position Angles in Children for Opening the Upper Airway. Resuscitation, 81, 676-678.

http://dx.doi.org/10.1016/j.resuscitation.2010.01.022

[26] Ishikawa, T., Isono, S., Aiba, J., Tanaka, A. and Nishino, T. (2002) Prone Position Increases Collapsibility of the Passive Pharynx in Infants and Small Children. American Journal of Respiratory and Critical Care Medicine, 166, 760-764.

http://dx.doi.org/10.1164/rccm.200110-044OC

[27] Safiruddin, F., Koutsourelakis, I. and de Vries, N. (2015) Upper Airway Collapse during Drug Induced Sleep Endoscopy: Head Rotation in Supine Position compared with Lateral Head and Trunk Position. European Archives of Oto-Rhino-Laryngology, 272, 485-488. http://dx.doi.org/10.1007/s00405-014-3215-z

[28] Reber, A., Paganoni, R. and Frei, F.J. (2001) Effect of Common Airway Manoeuvres on Upper Airway Dimensions and Clinical Signs in Anaesthetized, Spontaneously Breathing Children. British Journal of Anaesthesia, 86, 217-222. http://dx.doi.org/10.1093/bja/86.2.217

[29] Reber, A., Bobbià, S.A., Hammer, J. and Frei F.J. (2001) Effect of Airway Opening Manoeuvres on Thoraco-Abdominal Asynchrony in Anaesthetized Children. European Respiratory Journal, 17, 1239-1243. http://dx.doi.org/10.1183/09031936.01.00047801

[30] Shelton, K.E., Woodson, H., Gay, S. and Suratt, P.M. (1993) Pharyngeal Fat in Obstructive Sleep Apnea. American Revue of Respiratory Disease, 148, 462-466. http://dx.doi.org/10.1164/ajrccm/148.2.462

[31] Roth, B., Magnusson, J., Johansson. I., Holmberg, S. and Westrin, P. (1998) Jaw Lift-A Simple and Effective Method to Open the Airway in Children. Resuscitation, 39, 171-174. http://dx.doi.org/10.1016/S0300-9572(98)00132-4

[32] Von Ungern-Sternberg, B.S., Erb, T.O. and Frei, F.J. (2005) Jaw Thrust Can Deteriorate Upper Airway Patency. Acta Anaesthesiologica Scandinavica, 49, 583-585. http://dx.doi.org/10.1111/j.1399-6576.2005.00637.x 
[33] Atkins, D.L., Berger, S., Duff, J.P., Gonzales, J.C., Hunt, E.A., Joyner, B.L., Meaney, P.A., Niles, D.E., Samson, R.A. and Schexnayder, S.M. (2015) Part 11: Pediatric Basic Life Support and Cardiopulmonary Resuscitation Quality: 2015 American Heart Association Guidelines Update for Cardiopulmonary Resuscitation and Emergency Cardiovascular Care. Circulation, 132, S519-S525. http://dx.doi.org/10.1161/cir.0000000000000265

[34] Von Ungern-Sternberg, B.S., Erb, T.O., Reber, A. and Frei F.J. (2005) Opening the Upper Airway-Airway Maneuvers in Pediatric Anesthesia. Paediatric Anaesthesia, 15, 181-189. http://dx.doi.org/10.1111/j.1460-9592.2004.01534.x

[35] Prasarn, M.L., Horodyski, M., Scott, N.E., Konopka, G., Conrad, B. and Rechtine, G,R. (2014) Motion Generated in the Unstable Upper Cervical Spine during Head Tilt-Chin Lift and Jaw Thrust Maneuvers. The Spine Journal, 14, 609-614. http://dx.doi.org/10.1016/j.spinee.2013.06.080

[36] Oto, J., Li, Q., Kimball, W.R., Wang, J., Sabouri, A.S., Harrell, P.G., Kacmarek, R.M. and Jiang, Y. (2013) Continuous Positive Airway Pressure and Ventilation Are More Effective with a Nasal Mask than a Full Face Mask in Unconscious Subjects: A Randomized Controlled Trial. Critical Care, 17, R300. http://dx.doi.org/10.1186/cc13169

[37] Bruppacher, H., Reber, A., Keller, J.P., Geiduschek, J., Erb, T.O. and Frei, F.J. (2003) The Effects of Common Airway Maneuvers on Airway Pressure and Flow in Children undergoing Adenoidectomies. Anesthesia \& Analgesia, 97, 29-34. http://dx.doi.org/10.1213/01.ANE.0000069508.69518.97

[38] Perilli, V., Sollazzi, L., Bozza, P., Modesti, C., Chierichini, A., Tacchino, R.M. and Ranieri, R. (2000) The Effects of the Reverse Trendelenburg Position on Respiratory Mechanics and Blood Gases in Morbidly Obese Patients during Bariatric Surgery. Anesthesia \& Analgesia, 91, 1520-1525. http://dx.doi.org/10.1097/00000539-200012000-00041

[39] Genta, P.R., Schorr, F., Eckert, D.J., Gebrim, E., Kayamori, F., Moriya, H.T., Malhotra, A. and Lorenzi-Filho, G. (2014) Upper Airway Collapsibility Is Associated with Obesity and Hyoid Position. Sleep, 37, 1673-1678. http://dx.doi.org/10.5665/sleep.4078

[40] Ciscar, M.A., Juan, G., Martínez, V., Ramón, M., Lloret, T., Mínguez, J., Armengot, M., Marín, J. and Basterra, J. (2001) Magnetic Resonance Imaging of the Pharynx in OSA Patients and Healthy Subjects. European Respiratory Journal, 17, 79-86. http://dx.doi.org/10.1183/09031936.01.17100790

[41] Pien, G.W., Keenan, B.T., Marcus, C.L., Staley, B., Ratcliffe, S.J., Jackson, N.J., Wieland, W., Sun, Y. and Schwab, R.J. (2016) An Examination of Methodological Paradigms for Calculating Upper Airway Critical Pressures during Sleep. Sleep, 39, 977-987. http://dx.doi.org/10.5665/sleep.5736

[42] Shin, C.H., Zaremba, S., Devine, S., Nikolov, M., Kurth, T. and Eikermann, M. (2016) Effects of Obstructive Sleep Apnoea Risk on Postoperative Respiratory Complications: Protocol for a Hospital-Based Registry Study. BMJ Open, 6, e008436.

http://dx.doi.org/10.1136/bmjopen-2015-008436

[43] McNicholas, W.T., Bonsignore, M.R., Lévy, P. and Ryan, S. (2016) Mild Obstructive Sleep Apnoea: Clinical Relevance and Approaches to Management. The Lancet Respiratory Medicine, 4, 826-834. http://dx.doi.org/10.1016/S2213-2600(16)30146-1

[44] Sanders, M.H., Kern, N.B., Stiller, R.A., Strollo Jr., P.J., Martin, T.J. and Atwood Jr., C.W. (1994) CPAP Therapy via Oronasal Mask for Obstructive Sleep Apnea. Chest, 106, 774-779. http://dx.doi.org/10.1378/chest.106.3.774 
Submit or recommend next manuscript to SCIRP and we will provide best service for you:

Accepting pre-submission inquiries through Email, Facebook, LinkedIn, Twitter, etc. A wide selection of journals (inclusive of 9 subjects, more than 200 journals)

Providing 24-hour high-quality service

User-friendly online submission system

Fair and swift peer-review system

Efficient typesetting and proofreading procedure

Display of the result of downloads and visits, as well as the number of cited articles

Maximum dissemination of your research work

Submit your manuscript at: http://papersubmission.scirp.org/

Or contactijcm@scirp.org 